\title{
The self-medication practice in primary dysmenorrhea among pharmacy students-a cross-sectional questionnaire study
}

\author{
Sunitha Mahadevan*1, Dhanya Dharman², Deepa Manohar³, Shaiju S Daran4, Vismaya Annie Vinod', Aleena \\ Roy'
}

IIVth year Pharm D student, Ezhuthachan College of Pharmaceutical sciences, Trivandrum, Kerala, India.

${ }^{2}$ Department of pharmacy practice, Ezhuthachan College of Pharmaceutical sciences, Trivandrum, Kerala, India.

${ }^{3}$ Department of pharmaceutics, Ezhuthachan College of Pharmaceutical sciences, Trivandrum, Kerala, India.

${ }^{4}$ Department of Pharmacology, Ezhuthachan College of pharmaceutical Science, Trivandrum, Kerala, India.

\begin{abstract}
Primary dysmenorrhea is one of the most common gynaecological problems among adolescent females which interferes with daily activities, affecting their physical and emotional aspects and has a negative impact on quality of life. The pain is usually in the pelvis or lower abdomen. Self-medication for primary dysmenorrhea is a very common practice. The aim of this study was to observe and evaluate self-medication practice in primary dysmenorrhea among pharmacy students. This is a cross-sectional questionnaire study to be conducted among 50 females of age group between 18-25 of pharmacy college. The self-medication practice and features of dysmenorrhea were to be assessed with a 15 pre-validated questionnaire and the data is analyzed using descriptive statistics. A total of 50 students participated in this study in which $81.8 \%$ had regular periods. Dysmenorrhea was experienced in 79.6\% with mild (30.4\%),moderate(23.9\%) and with severe(28.3\%) dysmennohea. In this study $64.3 \%$ preferred self medication pattern. The majority were Pharm.D students. The most commonly used drug was Meftal spas (mephenamic acid+dicyclomine) and for $96.8 \%$ the treatment was found to be effective. Among the 50 students, $57.6 \%$ have experienced ADR , majority with decreased blood flow. The Self-medication practice in dysmenorrhea was more among pharmacy students probably due to the knowledge of drugs, better awareness and greater access to drug information during their curriculum. This highlights the importance of creating awareness among students to consume drugs only in severe discomfort after prescription by the registered medical practitioners.
\end{abstract}

Keywords: Dysmenorrhea, self medication practice.

ISSN: $2582-0672$

Research Article

\begin{tabular}{l}
\hline Corresponding Author \\
\hline \hline Name: Dhanya Dharman \\
Email: dhanyadharman07@gmail.com \\
\hline \hline
\end{tabular}

Article Info

Received on: 19-07-2019

Revised on: 04-08-2019

Accepted on: 12-08-2019

DOI: https://doi.org/10.33974/ijrhcp.v1i4.136

\section{Rubatọsis.}

Publications

Copyright $\odot$ 2019, Sunitha Mahadevan, et al., The self-medication practice in primary dysmenorrhea among pharmacy students-a cross-sectional questionnaire study, Production and hosting by Rubatosis Publications. All rights reserved.

\section{INTRODUCTION}

A normal female undergoes a myriad of changes in her body from puberty and thereafter. Puberty is a period of extreme stress and strain due to various physiological and psychological changes that occur. One of the major pubertal changes in girls is the onset of menstruation. Every mature female menstruates on an average of 3-5 days each month until menopause. Sometimes this cycle is associated with painful uterine contractions and discomfort known as dysmenorrhea. ${ }^{[1,2]}$ The prevalence of dysmenorrhoea in India is $62 \%$, and it varies greatly across different populations and ethnic groups. [3] Dysmenorrhea can be either primary or secondary.[4] Primary dysmenorrhoea is defined as painful menses in women with normal pelvic anatomy, usually beginning during adolescence. [5] The pain is usually spasmodic in characterand felt mainly in the lower abdomen, but it may radiate to the back and along the thighs. It is accompanied by some other symptoms and complications such as nausea, vomiting, diarrhea, headache, fatigue, dizziness, and in severe cases syncope. ${ }^{[6,7]}$ In essence, it is a symptom-complex which not only affects the 
quality of life but also reduces productivity. In students, it also has a negative impact on academic and daily activities. ${ }^{[1,8,9]}$ The major cause of dysmenorrhea is still not clear. It is said that prostaglandins (PGs) have a well-recognised pathophysiological role in primary dysmenorrhea by inducing intense uterine contractions, decreasing uterine blood flow, increasing peripheral nerve hypersensitivity resulting in pain or cramps.[10,11] The factors such as nulliparity, obesity, diet, family history of dysmenorrhea, stress, depression, cigarette smoking, and abuse are highly associated with the prevalence of primary dysmenorrhea.[12] Treatment for primary dysmenorrhea varies across different population worldwide, and includes lifestyle modification, complementary and alternative modalities, over-the-counter drugs, prescription analgesics and hormonal contraceptives. Prompt alleviation of the symptoms is necessary, failing which it may be responsible for the silent suffering among young women. Non-steroidal anti-inflammatory drugs (NSAIDs) and antispasmodics are commonly used drugs. NSAIDs such as ibuprofen, mefenamic acid, naproxen, ketoprofen, celecoxib, and diclofenac are proven to be effective by inhibiting cyclooxygenase leading to a reduction in PGs production. ${ }^{[10,11]}$ Antispasmodics such as dicyclomine and drotaverine act synergistically with NSAIDs to reduce the menstrual cramps, hence reducing the discomfort in primary dysmenorrhea.[10] Hormonal therapy in the form of oral contraceptive pills is reserved for patients with suboptimal or lack of response to NSAIDs.[13] Non-pharmacological home remedies commonly used are warm beverages, heat application, vitamin B1 or magnesium supplements, low-fat diet and herbal treatment.[6,14,15] Self-medication is termed as the use of medicines, specially designed and labeled for use without medical supervision and approved as safe and effective for such use.[16] They are called "over the counter" drugs and are available without doctor's prescription through pharmacies. Hence, this study was taken up to evaluate self-medication practice and to analyze the pattern of drugs use in primary dysmenorrhea among pharmacy students.

\section{METHODOLOGY}

A cross-sectional Questionnaire survey was conducted by online survey forms among pharmacy students with dysmenorrhea who willingly participated in this study ,after approval from the institutional ethical committee at Ezhuthachan College Of Pharmaceutical Sciences. 50 females of age group between 18-25 was included in this study for a period of 1 month. The self-medication practice and features of dysmenorrhea was assessed with a 15 pre-validated questionnaire and the data is analyzed using descriptive statistics.

Data collection: Data were collected during the 2018-2019 academic year. Respondents completed the online structured questionnaire forms which composed of check box questions regarding socio-demographic data, menstrual history, presentation of dysmenorrhea, and its impact on daily routine and social activities. Various remedial treatment methods practiced and health care seeking behavior to relieve dysmenorrhoea were recorded.

Statistical analysis: All data collected were analyzed using both descriptive and inferential statistics. The data were analyzed using descriptive statistics for demographic characteristics, menstrual history, dysmenorrhea, and its associated symptoms. The remedial methods used by the students such as self-medication, medical advice, home remedies for dysmenorrhea were analyzed and the value of $P<0.05$ was considered statistically significant.

\section{RESULTS}

A total of 50 students responded through Google forms, among which 36 had regular periods with an interval of 28-30 days and 9 had irregular periods Most of them had periods duration of $>3$ days with moderate blood flow. About 79\% of students have experienced discomfort during their menstruation ie, backache (95\%), nausea (47\%), vomiting (42\%), myalgia (31\%), diarrhea and micturition (2.4\%). Dysmenorrhea was experienced during first 2 days in $69.2 \%$,during premenstrual periods in $15.4 \%$ and throughout the cylcle in $17.9 \%$ of the subjects. remedies.In this study dysmennorhea was experienced in $79.6 \%$ with mild (30.4\%),moderate(23.9\%) and with severe $(28.3 \%)$ dysmennohea [Figure 1]. In this study $64.3 \%$ preferred self medication pattern [Figure 2]. The majority were Pharm D students. The most commonly used drug was Meftal spas [Figure 3] and for $96.8 \%$ the treatment was found to be effective [Figure 3]. Among the 50 students, 57.6\% have experienced ADR [Figure 4], majority with decreased blood flow [Figure 5].

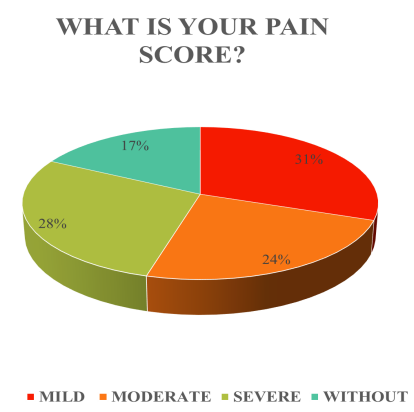

Figure 1: Plain score

\section{DISCUSSION}

Dysmenorrhea is the most common complaint in adolscent during clinical consultations .As a result of the enormous negative impact it has on activities of daily living making women opt for various options to alleviate the discomfort, ranging from drugs to 
household remedies. The main objectives of this study was:

- To observe and evaluate self-medication practice in primary dysmenorrhea among pharmacy students.

- To evaluate the commonly used OTC medicines for dysmenorrhea.

- To stress the importance of creating awareness among students to consume drugs only in severe discomfort after prescription by the registered medical practitioners.

In this study $64.3 \%$ preferred self medication pattern. The majority were Pharm D students. The most commonly used drug was Meftal spas and for $96.8 \%$ the treatment was found to be effective. Among the 50 students, $57.6 \%$ have experienced ADR, majority with decreased blood flow.
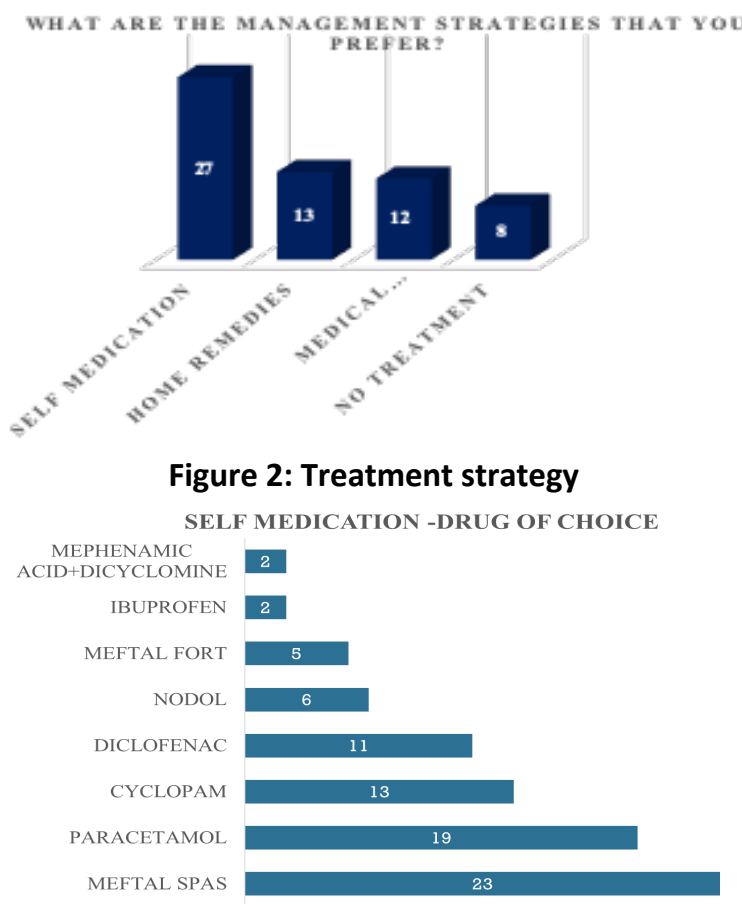

Figure 3: Drug of choice

IS THE TREATMENT EFFECTIVE?

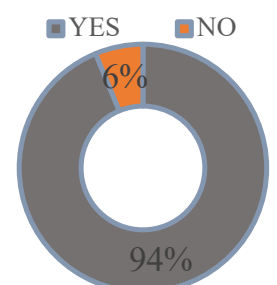

Figure 4: Drug of effectiveness

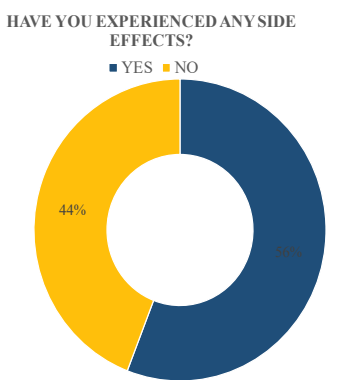

Figure 5: Occurrence of side effects COMMONLY EXPERIENCED SIDE EFFECTS

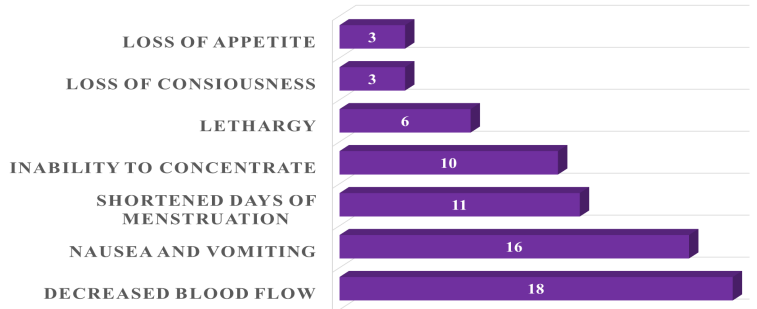

Figure 6: Common side effects

\section{CONCLUSION}

The Self-medication practice in dysmenorrhea was more among pharmacy students probably due to their knowledge of drugs, better awareness and greater access to drug information during their curriculum. But a significant number of students were unaware of the adverse effects of the medication that they take and suggest to others. This highlights the importance of creating awareness among students to consume drugs only in severe discomfort after prescription by the registered medical practitioners. The most Commonly used drugs in self-medication were mefenamic acid+dicyclomine, paracetamol, and cyclopam.

\section{ACKNOWLEDGEMENTS}

Authors would like to express sincere gratitude and respectful thanks to Prof.Shaiju S Daran, Principal, Ezhuthachan College of pharmaceutical sciences, Neyyantinkara for providing necessary facilities to carry out research. Also would like to thanks to faculty members of Department of Pharmacy Practice and friends of Ezhuthachan College of pharmaceutical sciences, Marayamuttom, Neyyattinkara for their constant support and help.

\section{CONFLICTS OF INTEREST}

The author declares no conflict of interests.

\section{REFERENCE}

1. Ezeukwu, A. O., Elochukwu, P. U., \& Ojukwu, C. P. (2014). Self-reported pain relief strategies for primary dysmenorrhea used by Nigerian female undergraduates. Int J Recent Sci Res, 5(1), 261-5.

2. Ganong, W. F. (1995). Review of medical physiology, 15 edn. 
3. Farotimi, A. A., Esike, J., Nwozichi, C. U., Ojediran, T. D., \& Ojewole, F. O. (2015). Knowledge, attitude, and healthcare-seeking behavior towards dysmenorrhea among female students of a private university in Ogun State, Nigeria. Journal of Basic and Clinical Reproductive Sciences, 4(1), 33-38.

4. Al-Asadi, J. N. (2013). Dysmenorrhea and its impact on daily activities among secondary school students in Basra, Iraq. Journal of the Faculty of Medicine, 55(4), 340-344.

5. Avasarala, A. K., \& Panchangam, S. (2008). Dysmenorrhoea in different settings: Are the rural and urban adolescent girls perceiving and managing the dysmenorrhoea problem differently?. Indian journal of community medicine: official publication of Indian Association of Preventive \& Social Medicine, 33(4), 246.

6. Parveen, N., Majeed, R., Zehra, N., Rajar, U., \& Munir, A. A. (2009). Attitude and knowledge of medical students of Isra University about dysmenorrhoea and its treatment. J Ayub Med Coll Abbottabad, 21(3), 159-62.

7. Jayanthi, B., \& Anuradha, H. V. (2014). Self-medication practice for dysmenorrhoea in medical, paramedical and non-medical students. International Journal of Pharmaceutical Sciences Review and Research, 27(1), 141-5.

8. Andersch, B., \& Milsom, I. (1982). An epidemiologic study of young women with dysmenorrhea. American journal of obstetrics and gynecology, 144(6), 655-660.

9. Klein, J. R., \& Litt, I. F. (1981). Epidemiology of adolescent dysmenorrhea. Pediatrics, 68(5), 661664.

10. Tripathi, K. D. (2013). Prostaglandins, leukotrienes and plateletactivating factor.

11. Grosser, T., Smyth, E., \& FitzGerald, G. A. (2011). Anti-inflammatory, antipyretic, and analgesic agents; pharmacotherapy of gout. Goodman and Gilman's the pharmacological basis of therapeutics, 12, 959-1004.

12.Akshara M, Varghese DM, Shaju MV, Joseph N, Tamrakar A. (2015). Dysmenorrhoea among adolescent girls in selected schools at Mangalore with view to develop and distribute an information booklet. J Nurs Health Sci. 4(1):34-9.

13. Ramya, S. (2012). A prospective study of the pattern of drug use in primary dysmenorrhea in a tertiary care hospital (Doctoral dissertation). Int J Res Pharmacol Pharmacother. 2014;3(1):80-4.

14. Simth PR, Kaunitz AM. Treatment of Primary Dysmenorrhoea in Adult Women. Available from: http://www.uptodate.com/ patients/content/topic.do. [Last accessed on 2016 Jun 09].

15. DeCherney HA. Dysmenorrhoea: Primary Dysmenorrhoea. ACP Medicine Online, Medscape General Medicine. Available from: http://www.medscape.com. [Last accessed on 2006 Oct 03]. 